Pacific Journal of Mathematic 


\title{
SPACES WHOSE FINEST UNIFORMITY IS METRIC
}

\author{
JOHN RAINWATER
}

Those metrizable spaces for which the finest uniform structure is induced by a metric have attracted a certain amount of attention, and M. Atsuji [1] has collected and extended a list of characterizations of them, regarded as uniform spaces. J. Nagata [6] and B. Levshenko [4] have given topological characterizations of these spaces. This note extends Atsuji's list and gives an analogous list of topological characterizations.

I am indebted to the referee for assistance with the references and improvements in the proofs.

Recall that a metric space (or a subset of a metric space) is said to be uniformly discrete if for some $\varepsilon>0$, the distance between two different points is always at least $\varepsilon$.

THEOREM 1. For a metric uniform space S, either of the following properties implies that the metric uniformity is the finest compatible with the topology; thus they are equivalent to the properties (1)-(8) of [1, Theorem 1].

(9) All bounded continuous real-valued functions are uniformly continuous.

(10) Every closed discrete subspace of $S$ is uniformly discrete.

THeORem 2. For a metrizable topological space $S$, the following properties are mutually equivalent:

(a) The finest uniformity on $S$ is a metric uniformity.

(b) The set of all non-isolated points of $S$ is compact.

(c) Every subset of $S$ has a compact boundary.

(d) Every closed set has a compact boundary.

(e) Every closed continuous image of $S$ is metrizable.

(f) Every Hausdorff quotient space of $S$ is metrizable.

(g) Every Hausdorff quotient space satisfies the first axiom of countability.

(h) Every closed set in $S$ has a countable basis of neighborhoods.

The equivalence of (a) and (b) in Theorem 2 is due to Nagata [6]. Levshenko has given three conditions equivalent to (b) [4]. One is that $S$ is a regular space having a countable family of locally finite converings such that every locally finite covering has a refinement in this family; the other two are obtained by replacing "locally finite" in both

Received November 10, 1958. 
places by "point-finite", and then by "star-finite". The mutual equivalence of (d), (e), and (h) is also essentially known; it follows at once from results obtained independently by A. H. Stone [7] and by K. Morita and S. Hanai [5].

Proof of Theorem 1. First, (9) implies (10). Suppose on the contrary that $T$ is a closed discrete subspace of $S$ which is not uniformly discrete. Then for each $n$ we can find two points $x_{n}, y_{n}$, in $T$, at distance less than $1 / n$ from each other; moreover, we can assure that $x_{n}$ and $y_{n}$ are distinct from the $2 n-2$ preceding points $x_{1}, \cdots, y_{n-1}$. Then the bounded real-valued function $f$ on $T$ which is 0 on all $x_{n}$ and 1 on all other points of $T$ is continuous, but not uniformly continuous. By Tietze's theorem, $f$ has a bounded continuous extension over $S$; this contradicts (9).

Next, (10) implies (4) of Atsuji's Theorem 1 [1], which says that any two disjoint closed sets have disjoint $\varepsilon$ neighborhoods for some $\varepsilon>0$. Suppose on the contrary that $A$ and $B$ are disjoint closed sets and $\left\{x_{n}\right\}$ a sequence of points in $S$, each $x_{n}$ common to the $1 / n$ neighborhoods of $A$ and $B$. No subsequence of $\left\{x_{n}\right\}$ has a limit point, for such a point would have to be in $A \cap B$; thus $\left\{x_{n}\right\}$ forms a closed discrete subspace of $S$. By (10), it is uniformly discrete; and since no subsequence has a limit point, it is infinite. Then there is a sequence $\left\{y_{m}\right\}$ of distinct points $x_{n}$ at distance at least $\varepsilon$ from each other, such that for each $y_{m}$ there are points $p_{m}$ in $A$ and $q_{m}$ in $B$ both within $1 / m$ of $y_{m}$. Again the $p_{m}$ and $q_{m}$ have no limit point; but they form a closed discrete subspace which is not uniformly discrete, a contradiction.

Finally, Atsuji shows [1] that (4) implies (8): "All continuous mappings of $S$ into an arbitrary uniform space $S^{\prime}$ are uniformly continuous ". Taking $S^{\prime}$ to be the topological space $S$ with its finest uniformity, we conclude that the given uniformity is the finest. Obviously this implies (9), and the proof is complete.

Proof of Theorem 2. To begin with, (a) is equivalent to $\left(a^{\prime}\right)$ : The diagonal in $S \times S$ has a countable basis of neighborhoods. For since $S$ is metric, the finest uniformity consists of all neighborhoods of the diagonal; and a uniformity is metric if and only if it has a countable basis [3, Chapter 6]. Now if (b) the set $N$ of all non-isolated points is compact, then the corresponding subset of the diagonal (being a compact subset of a metric space) has a countable basis of neighborhoods $V_{i}$. If we define $U_{i}$ as $V_{i}$ together with all the isolated points $(x, x)$ not in $V_{i}$, we have a countable basis $\left\{U_{i}\right\}$ about the diagonal. Thus (b) implies $\left(\mathrm{a}^{\prime}\right)$. Conversely, since $N$ is closed, if it is not compact it contains an infinite closed set of points $x_{n}$ whose distances from each other are bounded below by $\varepsilon>0$. Given any countable collection $\left\{U_{n}\right\}$ of 
neighborhoods of the diagonal, we can find a neighborhood of the diagonal $V$ which does not contain as large a neighborhood of $\left(x_{n}, x_{n}\right)$ as $U_{n}$ does (since $x_{n}$ is not isolated); thus no $U_{n}$ is contained in $V$, and $\left\{U_{n}\right\}$ is not a basis.

Thus (a) and (b) are equivalent. Now obviously $(b) \Rightarrow(c) \Rightarrow(d)$. For $(d) \Rightarrow(e)$, Stone has shown [7] that a particular closed continuous image of a metric space is metric if and only if all inverse images of points have compact boundaries. For $(\mathrm{e}) \Rightarrow(\mathrm{h})$, if $S$ had a closed subset $H$ having no countable basis of neighborhoods, the quotient space obtained by collapsing $H$ to a point would be the image under a closed mapping but not a metric space. Now we can deduce (b) from (h) in the same manner as from $\left(\mathrm{a}^{\prime}\right)$, using the supposed points $x_{n}$ in $S$ instead of $\left(x_{n}, x_{n}\right)$ in $S \times S$.

Trivially (f) $\Rightarrow(\mathrm{g}) \Rightarrow(\mathrm{h})$. It remains to prove $(\mathrm{b}) \Rightarrow(\mathrm{f})$. Let $Q$ be a Hausdorff space which is a quotient of $S$, with quotient mapping $f: S \rightarrow Q$. Then the image of $N$ is a compact metric subspace $P$ of $Q$. Every point of $Q-P$ is isolated, since its inverse image consists of isolated points and thus is open. We shall verify that $Q$ is a regular space with a $\sigma$-discrete base, and thus a metric space [3]. For regularity at a point $p$ of $P$, consider any closed set, $H$, not containing $p$. Since $H \cap P$ is a compact set in a Hausdorff space, $p$ has a closed neighborhood $F$ disjoint from $H \cap P$. Then $F-H$ is a still a neighborhood of $p$, since $H$ is closed; and $F-H$ is closed, since $H-P$ is open. Now for a base, let $\left\{U_{i}\right\}$ be a countable basis of neighborhood of $N$ in $S$. Each $f\left(U_{i}\right)$ is a neighborhood of $P$, because $f^{-1}\left(f\left(U_{i}\right)\right)$ is a neighborhood of $f^{-1}(P)$; and for every neighborhood $V$ of $P, f^{-1}(V)$ contains some $U_{i}$, so that $V$ contains $f\left(U_{i}\right)$. Let $\left\{B_{n}\right\}$ be a countable base for the space $P$. Each $B_{n}$ is $P \cap C_{n}$ for some open set $C_{n}$ in $Q$; let $D_{n i}=$ $C_{n} \cap f\left(U_{i}\right)$. To check that $\left\{D_{n i}\right\}$ constitutes a basis for each point $p$ of $P$, we must check that any closed set $H$ not containing $p$ is disjoint from some $D_{n i}$ containing $p$. There is a $B_{n}$ containing $p$ such that $\bar{B}_{n}$ does not meet $P \cap H$; then $\bar{C}_{n} \cap H$ and $P$ are disjoint, so there exists some $f\left(U_{i}\right)$ disjoint from $C_{n} \cap H$. But then $p \in D_{n i}$ and $D_{n i}$ does not meet $H$. Finally we adjoin the discrete collections $E_{i}$ of all single points in $Q-f\left(U_{i}\right)$; and the proof is complete.

REMARK. The concluding portion of the proof established the equivalence of $\left(b^{\prime}\right): S$ is a Hausdorff space in which the set of all nonisolated points is compact metric and has a countable basis of neighborhoods. This suggests the question whether the metrizability assumptions can be weakened or removed from any of the other conditions. It is easy to check that any compact perfectly normal space satisfies $(\mathrm{g})$ and (h); and the standard example [2, p. 31, Problem 19] Palso has the 
property that every closed subset has a compact metric boundary. Note, however, Levshenko's conditions [4].

\section{REFERENCES}

1. M. Atsuji, Uniform continuity of continuous functions of metric spaces, Pacific J. Math. 8 (1958), 11-16.

2. N. Bourbaki, Topologie Générale, Chap. IX, Act. Sci. Ind. 1045, Hermann, Paris, 1948.

3. J. L. Kelley, General topology, Van Nostrand, New York, 1955.

4. B. T. Levshenko, On the concept of compactness and point-finite coverings, Mat Sbornik 42 (84) (1957), 479-484.

5. K. Morita and S. Hanai, Closed mappings and metric spaces, Proc. Japan Acad. 32 (1956), 10-14.

6. J. Nagata, On the uniform topology of bicompactifications, J. Inst. Polytech. Osaka City University 1 (1950), 28-38.

7. A. H. Stone, Metrizability of decomposition spaces, Proc. Amer. Math. Soc 7 (1956), 690-700.

\section{UNIVERSITY OF WASHINGTON}




\section{PACIFIC JOURNAL OF MATHEMATICS}

\section{EDITORS}

\section{David Gilbarg}

Stanford University

Stanford, California

\section{R. A. Beaumont}

University of Washington

Seattle 5 , Washington

\author{
A. L. Whiteman
}

University of Southern California Los Angeles 7, California

L. J. Paige

University of California

Los Angeles 24, California

\author{
E. F. BECKENBACH \\ C. E. BURGESS \\ E. HEWITT \\ A. HORN
}

\author{
V. GANAPATHY IYER \\ R. D. JAMES \\ M. S. KNEBELMAN \\ L. NACHBIN
}

ASSOCIATE EDITORS
I. NIVEN

T. G. OSTROM

H. L. ROYDEN

M. M. SCHIFFER
E. G. STRAUS

G. SZEKERES

F. WOLF

K. YOSIDA

\section{SUPPORTING INSTITUTIONS}

\author{
UNIVERSITY OF BRITISH COLUMBIA \\ CALIFORNIA INSTITUTE OF TECHNOLOGY \\ UNIVERSITY OF CALIFORNIA \\ MONTANA STATE UNIVERSITY \\ UNIVERSITY OF NEVADA \\ OREGON STATE COLLEGE \\ UNIVERSITY OF OREGON \\ OSAKA UNIVERSITY \\ UNIVERSITY OF SOUTHERN CALIFORNIA
}

\author{
STANFORD UNIVERSITY \\ UNIVERSITY OF TOKYO \\ UNIVERSITY OF UTAH \\ WASHINGTON STATE COLLEGE \\ UNIVERSITY OF WASHINGTON \\ * * * \\ AMERICAN MATHEMATICAL SOCIETY \\ CALIFORNIA RESEARCH CORPORATION \\ HUGHES AIRCRAFT COMPANY \\ SPACE TECHNOLOGY LABORATORIES
}

Mathematical papers intended for publication in the Pacific Journal of Mathematics should be typewritten (double spaced), and the author should keep a complete copy. Manuscripts may be sent to any one of the four editors. All other communications to the editors should be addressed to the managing editor, L. J. Paige at the University of California, Los Angeles 24, California.

50 reprints per author of each article are furnished free of charge; additional copies may be obtained at cost in multiples of 50 .

The Pacific Journal of Mathematics is published quarterly, in March, June, September, and December. The price per volume (4 numbers) is $\$ 12.00$; single issues, $\$ 3.50$. Back numbers are available. Special price to individual faculty members of supporting institutions and to individual members of the American Mathematical Society: $\$ 4.00$ per volume; single issues, $\$ 1.25$.

Subscriptions, orders for back numbers, and changes of address should be sent to Pacific Journal of Mathematics, 2120 Oxford Street, Berkeley 4, California.

Printed at Kokusai Bunken Insatsusha (International Academic Printing Co., Ltd.), No. 6, 2-chome, Fujimi-cho, Chiyoda-ku, Tokyo, Japan.

PUBLISHED BY PACIFIC JOURNAL OF MATHEMATICS, A NON-PROFIT CORPORATION

The Supporting Institutions listed above contribute to the cost of publication of this Journal, but they are not owners or publishers and have no responsibility for its content or policies. 


\section{Pacific Journal of Mathematics}

\section{Vol. 9, No. $2 \quad$ June, 1959}

Lee William Anderson, On the breadth and co-dimension of a topological lattice

Frank W. Anderson and Robert L. Blair, Characterizations of certain lattices

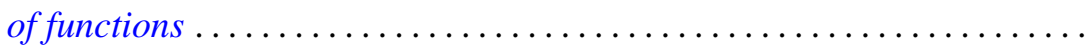

Donald Charles Benson, Extensions of a theorem of Loewner on integral

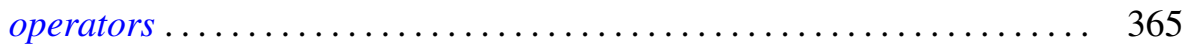

Errett Albert Bishop, A duality theorem for an arbitrary operator ........ 379

Robert McCallum Blumenthal and Ronald Kay Getoor, The asymptotic distribution of the eigenvalues for a class of Markov operators ........

Delmar L. Boyer and Elbert A. Walker, Almost locally pure Abelian

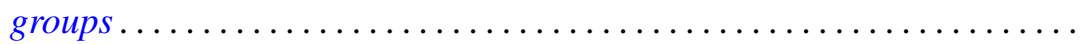

Paul Civin and Bertram Yood, Involutions on Banach algebras ........... Lincoln Kearney Durst, Exceptional real Lehmer sequences .... 415

Eldon Dyer and Allen Lowell Shields, Connectivity of topological

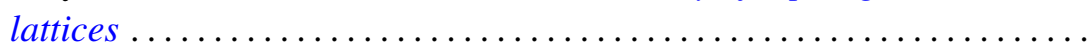

Ronald Kay Getoor, Markov operators and their associated

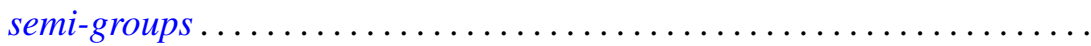

Bernard Greenspan, A bound for the orders of the components of a system of algebraic difference equations

Branko Grünbaum, On some covering and intersection properties in

Minkowski spaces ............................

Bruno Harris, Derivations of Jordan algebras ..............

Henry Berge Helson, Conjugate series in several variables.

Isidore Isaac Hirschman, Jr., A maximal problem in harmonic analysis.

II .

Alfred Horn and Robert Steinberg, Eigenvalues of the unitary part of a matrix

Edith Hirsch Luchins, On strictly semi-simple Banach algebras ...

William D. Munro, Some iterative methods for determining zeros of

functions of a complex variable...

John Rainwater, Spaces whose finest uniformity is metric .

William T. Reid, Variational aspects of generalized convex functions ....

A. Sade, Isomorphisme d'hypergroupoï des isotopes ...... . .

Isadore Manual Singer, The geometric interpretation of a special

connection . . .

Charles Andrew Swanson, Asymptotic perturbation series for characteristic

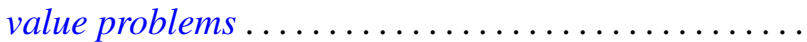

